\title{
Mise-en-film da fotografia em três documentários brasileiros
}

\author{
Glaura Cardoso Vale
}

Resumo: Este artigo busca analisar, em três filmes da cinematografia brasileira recente, os modos como a fotografia, entendida como dispositivo de rememoração, é colocada em cena, compreendendo-a como rastro da presença de algo que já se tornou ausente. Pretende-se discutir como, ao solicitar imagens retiradas dos "álbuns de família", corrobora-se a construção de narrativas que dão a ver a biografia de homens e mulheres comuns, reais ou imaginados pelo documentário. Verificar, em metodologias distintas, o exercício político e estético do fazer cinematográfico que expõe as fragilidades e possíveis frustrações na reconstrução de algo longínquo (do ponto de vista do personagem) e desconhecido (do ponto de vista dos autores), por mais presente materialmente que esteja a imagem no ato da rememoração.

Palavras-chave: documentário brasileiro contemporâneo; dispositivo; arquivo familiar.

Abstract: The photography's mise-en-film in three Brazilian documentaries - This paper analyzes the ways the photography (as a remembering device) is put into play in three recent movies of Brazilian cinema, understanding it as a trace of the presence of something that has already become absent. The aim is to discuss how images taken from family albums can support the narrative construction that unfolds the life of ordinary men and women, either realistic or imagined by the documentary. Moreover, based on different methodologies, this paper examines the political and aesthetical exercise of a film-making. This analysis exposes the weaknesses and possible frustrations in the reconstruction of the remote (the character's point of view) and the unknown (the authors' point of view), even if the image in the act of remembrance is materially present.

Keywords: contemporary Brazilian documentary; device; family archive.

Narrar a partir das imagens, apoiar-se na sua materialidade, ao menos, nos vestígios que nela resistem - recurso fortemente verificável na filmografia brasileira, sendo Eduardo Coutinho talvez um dos maiores expoentes na aplicação desse método, traduzindo esse gestual como parte do encontro com as pessoas filmadas -, este artigo intenciona mostrar e discutir em três documentários brasileiros como o gesto de solicitação da fotografia, entendido como dispositivo de rememoração, corrobora a construção de camadas 
temporais que se entrecruzam internamente (no tecido fílmico) e quais aproximações engendra exteriormente à narrativa. A vida de homens e mulheres comuns, seus anseios e o que o futuro lhes reservou, sendo a fotografia apenas uma chave para o passado rememorado, embora não se possa restituí-lo, sobretudo trazer de volta vidas interrompidas: Acácio (2008), de Marília Rocha, com um etnógrafo português que viveu em Angola até a década de 1970; Nos olhos de Mariquinha (2008), de Cláudia Mesquita e Junia Torres, com uma antiga moradora da Vila Nossa Senhora de Fátima, em Belo Horizonte; e Moscou (2009), de Eduardo Coutinho, com o grupo teatral Galpão, convidado a ensaiar As três irmãs de Tchekhov, peça que não será montada.

Os três filmes podem ser considerados "biográficos", embora em Moscou isso se dê de forma mais complexa e opaca, já que apresenta vários sujeitos e, assumidamente, trabalha no plano da encenação de múltiplas biografias buscadas ora na obra teatral, ora no empréstimo das vivências dos próprios atores e atrizes. Conforme Cláudia Mesquita define, ao tratar de Santiago (2007), de João Salles, Acácio (2008), de Marília Rocha, Pan-cinema permanente (2008), de Carlos Nader (sobre Waly Salomão) e Vida (2008), de Paula Gaitán (sobre Maria Gladys):

Se uma biografia mais tradicional - como Jango - enumera feitos, amarra fatos numa cadeia causal, enaltece, encerra significações, os filmes aqui analisados ficam mais bem definidos como "retratos": em primeiro lugar, porque abordam os sujeitos vivos (na filmagem, ao menos), valorizando o encontro contingente, o "instante minúsculo" e o que dele resulta - mesmo que haja neles, também, uma medida biográfica, já que a dimensão contingente do retrato se articula, de diferentes maneiras, com a construção de uma trajetória no tempo para o retratado. São "retratos", ainda, porque neles o retratista se implica; tematizando o processo de "retratar", os filmes não se apresentam como cópias, mas como composição dos personagens segundo a perspectiva daquele que retrata e segundo a relação em que ambos (cineasta, personagem) se engajam. (MESQUITA, 2010)

Além de compor retratos das pessoas filmadas, como Cláudia Mesquita aborda em seu texto, o retrato em sua forma material, ao ser solicitado, apresenta um caráter metonímico, por sintetizar em cada fotografia um recorte de sentimentos e histórias que se abrem ao espectador todas as vezes que o "álbum de família" é "manuseado". Sem pretender adentrar em questões relativas ao gênero biográfico e ao retrato que os cineastas constroem em diálogo com os personagens, ${ }_{1}^{1}$ percebe-se essas duas dimensões (biográfica e da construção em diálogo) condensadas metonimicamente na cena (no narrar por imagens), gerando um efeito de mise-en-abyme que nos remete para o próprio fazer cinematográfico. A elaboração do trauma, em Nos olhos de Mariquinha (a perda do neto), Acácio (a experiência da guerra colonial e a condição de retornado) e Moscou (os afetos

1 Mesmo porque, em Moscou, Eduardo Coutinho se ausenta da cena. 
desfeitos e a inocência perdida), é fundamental para que os filmes se façam. Elaboração no sentido de tessitura, como Gagnebin (2014, p. 235-236) observa em relação ao trabalho da rememoração de Penélope em Benjamin: "o movimento duplo dos fios, a dinâmica do esquecer e do lembrar" em que ambos são ativos. Fala e fotografia não podem ser pensadas como processos distintos e independentes nos filmes em análise, pois compõem a sua urdidura, por mais que em Nos olhos de Mariquinha a solicitação não seja estrutural e sim pontual. Para a pesquisadora portuguesa Isabel Capeloa Gil:

Os retratos de família, as recordações de viagem, de festas e dias comemorativos, quiçá de múltiplos outros (de seres humanos a animais, paisagens e espaços edificados) que se cruzam com o fotógrafo, constituem formas prismáticas de compor o espaço da memória, de articular invisibilidades, tensões, afinal, estilhaços que em óptica pós-moderna permitem contar uma miríade de histórias de múltiplas perspectivas. (2012, p. 168)

Pensando nessas "formas prismáticas de compor espaços da memória", de que nos fala Capeloa Gil, e de acordo com Philippe Dubois (2012, p.2), que trabalha a mise-en-film da fotografia em Agnès Varda, Chris Marker, Hollis Frampton, Raymond Depardon, Robert Frank, procuro "praticar intencionalmente um enviesamento", acreditando, assim como o crítico defende, que, entre cinema e fotografia, existe uma massa considerável "de problemáticas transversais, de casos de figuras relativamente ricas e singulares" (DUBOIS, 2012, p. 2). Inspirada nesse exercício de análise proposto por Dubois, busco perceber como esse gesto de solicitação da fotografia se dá para e com o outro, na construção da memória das pessoas filmadas, mesmo que esteja em jogo a elaboração da memória de seres inventados. Em Moscou, por exemplo, a fotografia é apropriada como elemento cênico, como as imagens coladas numa caminha de boneca, conforme se verá mais adiante, ou fixadas no espelho do camarim, por vezes como presença de um corpo ausente, passível de ser interrogado, direcionando à imagem um acerto de contas. Lembramos, aqui, da cena do ator Júlio Maciel com o retrato aparentemente do próprio pai colocado sobre uma cadeira. O personagem, embriagado, comunica ao pai - presente na imagem - o título de conselheiro que acabou de receber e serve a ambos uma dose de bebida. O tom é amargo. Nesse momento, o ator, em busca de seu personagem, também exibe imagens de ultrassonografias do filho que nascia nesse processo de Moscou, conforme nos é informado aos 15 minutos do filme. Encenar com as fotografias, corpos impressos em material sensível colocados em movimento. Diferentemente de Acácio e Nos olhos de Mariquinha, Moscou elege atores para ficcionalizar a partir do embaralhamento de lembranças pessoais com os relatos dos outros atores, para daí traçar o perfil, ainda que incompleto, da memória dos personagens do texto de Tchekhov - uma narrativa de encaixes que expõe a pesquisa do ator à procura dos personagens. 
Em Acácio e Nos ollhos de Mariquinha, o diálogo é uma das estratégias que garantem, propriamente, o lugar da palavra na enunciação fílmica, mesmo que por vezes as vozes das diretoras estejam em suspensão, ou silenciadas pela montagem, a escuta ao menos se faz presente - como Dona Mariquinha mesmo diz, referindo-se à equipe do filme em um momento de visita à Rádio Favela, aproximadamente aos 21 minutos: "Mas isso aí, meu filho, trabalha que nem nunca. Eles ficam calados. Eles não podem conversar não. Nós pode". A fotografia cumpre um papel importante na narração de ambos, sendo um elemento fortemente estético, no primeiro, dado o impacto que as imagens de arquivo de rituais e do cotidiano em Angola provocam, no segundo, porque constitui uma política contra o desaparecimento. Em Nos olhos de Mariquinha, essa solicitação se dá pontualmente, num momento importante para a compreensão de seu alerta em relação às notícias de assassinato no aglomerado onde vive; já em Acácio, que trabalhou para o Museu etnográfico do Dundo, ${ }^{2}$ permeia toda a narrativa - a iconografia solicitada é, como método, o que garante o narrar.

Em Acácio, entrecruzam-se vários tempos: a infância e juventude em Trás-osMontes; a vida em Angola, onde os filhos cresceram, o traumático momento de fuga do território antes de decretada a independência do país em 1974, a chegada em Portugal na condição de retornados e a vinda para o Brasil (ambas correspondendo ao passado); e o tempo presente (onde se dá a rememoração, bem como imagens de Portugal e de Angola recentes). ${ }^{3}$ A memória, em boa parte, é mediada pelo visionamento do material produzido pelo etnógrafo e por imagens atuais coletadas pela equipe, permitindo que os personagens possam reviver um tempo passado no presente. É, por assim dizer, dentre os três, o filme mais complexo em camadas temporais e utilização de registros.

De acordo com Comolli, "o cinema documentário, ao ceder espaço ao real, que o provoca e o habita, só pode se construir em fricção com o mundo" (COMOLLI, 2008, p.173). Nessa passagem bastante conhecida de Ver e poder, Comolli (ibidem, p.177) nota que, "mesmo que quisesse, a obra documental seria incapaz de reduzir o mundo a um dispositivo que ela daria como pronto" (2008, p. 177). Acredita-se que o mesmo ocorre em Acácio, Nos olhos de Mariquinha e Moscou que, a meu ver, não pretendem reduzir o mundo ao dispositivo, ao contrário, o tornam uma janela para acessar o mundo, a partir do interior da casa de seus personagens e de suas caixas de retratos. Os filmes buscam um duplo movimento. Ao se concentrarem na esfera do vivido, encontram também o fora, uma vez que só podem empurrar as imagens solicitadas para um futuro (LISSOVSKY, 2012, p. 5) ainda que esse futuro se encerre provisoriamente na tessitura fílmica -, por estarem abertos

2 Museu pertencente à extinta empresa portuguesa de exploração de diamantes (Diamang).

3 Sobre isso, em 2008, para a pesquisa do filme Acácio, escrevi o texto "Memórias para um filme, a trajetória de Acácio", publicado posteriormente no Minas Gerais, Suplemento Literário (mar. 2009), com o título: Acácio Videira, personagem de um filme. Vale ainda verificar o texto "Pensando em Acácio", de Cláudia Mesquita (2009), e "Acácio: a escritura do cinema encontra a escrita da memória", de Victor Guimarães (2010), disponíveis em:

$<$ http://www.mariliarocha.com/trabalhos/acacio $>$. 
a uma possibilidade de ressignificação, pela impossibilidade de reduzi-las e submetê-las a uma verdade acabada. O fora aqui pode ser tanto o fora de campo, quanto as projeções imaginárias que incidem no campo, no ato da rememoração, sobre algo que não se pode apreender materialmente (pela distância temporal, pela ausência de um ente). Tais filmes operam num sistema de forças que busca potencializar o narrar, por mais vacilante e frágil que seja a fala, por mais gastas que estejam as palavras (e as imagens?), por mais inacessível que esteja o passado (e seus mortos), embora a fotografia possa ser "prova" material do tempo vivido ou de uma existência. O uso dessas imagens fotográficas parece evidenciar, nessas abordagens, algo comum: a partilha de um filme por vir.

\section{Acácio: lembrar é sempre um ato de saudade}

O gesto de colocar a fotografia em cena está apenas sugerido em Acácio. O personagem olha, mas o espectador não vê o que ele olha, não imediatamente. O que ele vê só é revelado como uma projeção de imagens de arquivo selecionadas pela montagem, por vezes coincidente com o relato, por vezes não. O que temos desses registros será sempre uma seleção que embaça essa zona fronteiriça entre o que é dito e o que é visto. As imagens estão concentradas no acervo produzido pelo personagem e, basicamente , na sua vida em Angola. Destaco uma das cenas em volta da mesa, a 28min do início do filme, em que o personagem olha cuidadosamente imagens que estão fora de campo e é impedido de tocá-las pela esposa, Maria da Conceição. Há ali uma identificação das festas, dos espaços, e um conflito de memórias. Acácio, concentrado, pede que a esposa espere e encontra um nome: "é o Sacamanda!". Ele constata e ela diz: "não é não". "É sim. É o Sacamanda sim. Não é tão velho como quando morreu", insiste. "Ah, o velhote?" Dona Conceição se dá por vencida. A memória, disputada de maneira aparentemente trivial pelo casal, nesse jogo "é"/"não é não", exige do personagem extrema atenção. A fotografia, como pode ser constatado, permite acrescentar nova informação, contudo, a tessitura fílmica encontra potência também no esquecimento, se apropriando do tempo intervalar da rememoração, do rosto do personagem, dos olhos contraídos e atentos buscando por um nome, expressões que revelam o dentro e o fora das imagens.

O acervo de Acácio se divide em duas partes, como etnógrafo, retratou o cotidiano e os rituais dos Tchokwe (quiôco na tradução portuguesa) e, como colono, a vida na pequena cidade onde estes viviam, colecionando, em seus momentos de lazer, também imagens da vida colonial na África. Ao voltar a câmera para si mesmo, imprime dois mundos em contraste e as contradições do colonialismo se fazem visíveis na imagem (uma reunião de amigos, descontraídos, Maria da Conceição no canto esquerdo, sempre sorrindo, e um único negro, no canto direito, como uma escultura, provavelmente um empregado, a segurar uma criança). Foi necessário lançar mão de um procedimento de rememoração, rever sistematicamente as imagens retiradas de pastas e álbuns de família, 
para reavivar a memória, posteriormente reordenada pela montagem. Dar uma linearidade a algo descontínuo, não apenas pela memória que é falhada e fragmentada, mas pela fragmentação também territorial. Nesse sentido, o filme não só trabalha a descontinuidade da memória, como se apropria dela. O filme dá a essa memória uma dimensão, tal qual é apresentada à equipe, de confinamento: o personagem já idoso, na sua casa, revendo seus arquivos, enquanto o passado, sobretudo em Angola, é uma imagem inalcançável.

\section{Nos olhos de Mariquinha: um contra-campo possível}

Tendo como fio narrativo e personagem central uma antiga moradora de uma vila de Belo Horizonte, Nos olhos de Mariquinha trabalha a memória em pelo menos duas perspectivas: a memória recente - das mudanças ocorridas na vila e da perda de parentes - e o passado longínquo - o da exploração do trabalho no campo. Diferenciando-se da câmara confessional de Acácio, a personagem Mariquinha transita entre os espaços íntimos, o da casa, e o público, becos e ruelas, bem como na Rádio Favela, cuja voz ganha outros territórios, outras ruas e bairros - por ela lembrados ao enviar um abraço a todos os ouvintes de Belo Horizonte.

A mise-en-film da fotografia surge nos 20 minutos finais, numa passagem chave para compreensão da complexidade de uma vida construída sob a insegurança e ameaça de um jogo de forças entre o tráfico e a repressão das autoridades. Obrigados a conviver cotidianamente com uma realidade violenta, em que os jovens negros são os mais atingidos, numa expectativa de vida abaixo de 29 anos, ${ }^{4}$ o filme não aborda essa questão diretamente, mas a presentifica quando o episódio de um assassinato na mercearia Goiabal, a que a personagem dá enorme atenção, ganha importância na tessitura fílmica e, em consequência, nesse gesto de solicitar a fotografia. A busca pelo nome de quem foi morto, a busca inquieta de Mariquinha por um rosto, é a busca de quem não é somente mãe e avó, mas de quem perdeu muitos dos seus entes assassinados. Saber quem morreu é saber que um dos seus ainda se mantém vivo. Todas as pistas dadas antes pela palavra retornam e se materializam no que sobrou de seu álbum de família. Nesse sentido, um dos encontros mais fortes do filme parece ser este: o da personagem com seus retratos.

Em sua casa, Mariquinha exibe algumas poucas fotografias que conseguiu recuperar: um ex-companheiro, o neto, a filha ainda pequena com uma bacia de lavar roupa. São imagens atravessadas pela ausência, mas também pela ternura. Aqui, chamo a atenção para as duas fotografias do neto que se tornam potência reveladora de uma ausência presente. Morto na porta de casa, talvez seja a lembrança mais traumática da personagem revelada para o filme. Ao mesmo tempo em que evoca a presença do neto, na força

4 Esses dados podem ser consultados no Mapa da Violência do sociólogo argentino Julio Jacobo Waiselfiszs. Conferir também artigo de Viviane Tavares, "Brasil tem como principal causa de morte entre jovens o homicídio". In: Revista Fórum, 4 fev., 2013. 
da rememoração, a fotografia é a constatação de uma imagem sem corpo, identificando a aporia nessa relação de ausência que se faz presença e vice-versa.

Ao solicitarem a abertura de uma "pasta" ou "caixa de retratos" - já não mais o álbum sobrevive na sua materialidade -, inspiradas talvez pelo método de Eduardo Coutinho, Cláudia Mesquita e Junia Torres cumprem o papel de escavar vestígios de histórias oprimidas. As realizadoras permitem que tais imagens adentrem na porosidade da narrativa, experiência até então restrita àqueles que a viveram, e o filme reivindica, desse modo, uma política contra o desaparecimento. Nesse momento, a memória da personagem passa a pertencer também ao espectador, sensível à tragédia dos homens, assim se espera, nomeando aquele que, para os dados oficiais, pertencia apenas a uma estatística, ao Mapa da Violência. O neto de Mariquinha, criado por ela desde que nasceu, deixa de ser um número e o filme lhe confere uma certa integridade, permite que agora tenha um nome: José Roberto. A fotografia reencontra um nome. É evidente que um filme não irá reparar essa perda, contudo, é capaz de reinserir esse jovem na linha do tempo, recapturá-lo - perante os nossos olhos - do esquecimento, imagem pensante ou que nos faz pensar. Isso está posto ao menos duas vezes em cena: a mão da personagem segurando o retrato e o momento em que a fotografia é colocada em tela cheia. No instante em que o retrato preenche todo o quadro, convoca mais uma vez o espectador para a reflexão. O retrato de Dona Mariquinha com o neto, ela e ele, no dia da formatura de José Roberto, apresentado de frente para o público, não seria um contra-campo ${ }^{5}$ possível à cena em que Acácio olha e fora do quadro estão vestígios de um tempo, lugares, pessoas que também aguardam por um nome? Para além das funções que exerce em sua comunidade (costureiro, caçador, dançarino, feiticeiro), funções catalogadas pelos museus, o velho feiticeiro na fotografia tem nome: Sacamanda. Para Acácio, uma África duplamente inalcançável, temporalmente e quando, impedido pela esposa, "não põe a mão", tem o desejo de tocar reprimido; para Dona Mariquinha, uma perda irreparável, resta segurar a imagem do neto com a mão firme. Contra-campo no sentido que nos ensina Godard em Nossa música (2004): "a verdade tem duas faces".

A África de Videira representa o elo perdido, ao menos o do imaginário dos colonos, e a foto de Mariquinha com o neto, o "real" que confronta certo imaginário "imperial" que, segundo Margarida Calafate Ribeiro, se manteve mesmo em relação à África no fim do século XIX e limiar do século XX, perpetuando a ideia "da Índia e dos mares até lá navegados, de que este império é saudade e memória" (RIBEIRO, 2004, p. 15). Resta àqueles que descendem desse imaginário reclamarem o real que lhes cabe? Um território, a existência enquanto indivíduos, a dignidade, a liberdade, seus rituais, a ressignificação na história, um nome, portanto: "José Roberto". Não podemos com isso, obviamente,

5 No mini-curso "Exercícios de Cinema Comparado" (PPGCOM-UFMG, out. 2014), Mateus Araújo Silva propôs essa relação de campo/contra-campo entre São Paulo S/A (1965, Sérgio Person) e O bandido da Luz vermelha (1968, Rogério Sganzerla), reflexão que possibilitou pensar essa relação também entre filmes muito distintos. 
simplificar os processos, mas lembrar a necessidade de uma reparação histórica em que os retratos recuperados pelos filmes acabam por compor um memorial.

Enquanto Acácio permanece confinado nas próprias lembranças, nas suas aventuras juvenis, na promessa frustrada de uma nova vida em Angola, Dona Mariquinha só tem o futuro como saída - em relação a um passado que constata a falência, não do seu projeto de busca, mas da nossa própria sociedade. Em vez de se amargurar, ela sorri e fala eloquentemente sobre tudo e amplia essa voz no microfone da rádio comunitária que ajudou a fundar.

\section{Moscou: a cidade da (im)possibilidade}

Afinal, para que serve vasculhar os álbuns de família? Por que adentrar a vida de personagens anônimos e pedir que elaborem uma memória compartilhável? É possível tornar a história de uma pessoa comum uma história comum a todos? Mais especificamente, a que serve propor a um grupo de teatro o trabalho de preparação de uma peça que não será encenada? A criação desconcertante para a câmera possibilita ao ator desprender-se de si mesmo, reconhecer-se frágil, deixar transparecer um processo de construção cujo objetivo já é dado como inacabado? Passar do "Eu" ao "Ele" (Blanchot) ofuscando essa passagem?

Moscou é um filme-ensaio de uma peça, As três irmãs, de Tchékhov, que não tem como objetivo final a estreia, ou seja, um filme sobre o "não por vir". No caso, a peça que se ensaia é o próprio filme Moscou. Cidade projetada pelos personagens como o lugar possível, onde talvez os laços de uma infância feliz possam ser reestabelecidos. Enquanto projeção, a cidade é o Fora, assim como o Dundo para Acácio, com a diferença de que em Moscou persiste a possibilidade de ir - não sendo um Fora como imagem de passado, é um Fora em futuro. O filme é todo ele um jogo ambíguo, lançando mão do exercício do ator de seguir algumas indicações do diretor e do texto, apropriando-se da memória afetiva, sobrepondo camadas, outra pele, portanto. A memória a que a peça de Tchekhov incita é uma reinvenção também do método coutiniano de fazer documentário. O diretor sai de cena, como presença física e perquiridora, para assumir o lugar do narrador. Não aquele que tudo sabe, mas aquele que põe radicalmente em risco a possibilidade de filme. A aparição de Coutinho é precisa, apresenta o projeto, convoca Enrique Diaz como diretor da peça e permite que os atores se reinventem "presos" numa caixa cênica o lugar de ensaios do grupo em Belo Horizonte -, sendo a câmera a quarta parede. Ilana Feldman refere-se a um sujeito duplamente dissolvido atrás da câmera que, ao recolher sua inquieta presença, deixa "suas marcas no negro espaço do galpão" (In: OHATA, 2013, p. 646). Porém, o maior desafio de Moscou consiste em borrar da perspectiva dos atores o fim, a montagem que vislumbra o espetáculo. O que resultará dessa experiência será algo intermediário para eles. O filme parece trabalhar com esse limiar. 
Em Moscou, ${ }^{6}$ fala-se de um passado imaginado, de seres imaginários e separados deles mesmos. A fotografia solicitada permeia todo o filme e penetra a cena; sendo algo estruturante em Moscou, desde o primeiro plano, uma imagem-cidade, como algo que desencadeia lembranças (uma praça, um cinema) coladas ao corpo, embaladas por uma canção, ou mesmo numa comparação jocosa entre os meninos da fotografia que tem em mãos e os sobrinhos do Pato Donald que Paulo André faz. Mas a cena que mais me desperta atenção, nesse sentido, é a da atriz Lydia del Picchia, que interpreta Natacha, a cunhada das três irmãs. Enquanto cantarola, embala sobre o seu peito duas fotografias que exibe frontalmente. Uma delas não se pode identificar pelo reflexo da luz, a outra é visivelmente uma fotografia da atriz mais jovem. A alegria alojada no passado é ressignificada no presente, e o cantarolar desperta um tempo ausente: a juventude da atriz emprestada à personagem. Essa juventude e delicadeza do cantarolar recebem nova roupagem posteriormente, quando ela se torna a megera Natacha, adquirindo um figurino sombrio de época e rispidez na voz. Aos poucos, a personagem se distancia desse momento em que a voz suave diz: "e eu vou encher o pote, pra ter água pra levar". Cochicha e continua: "Mas eu vou me casar um dia e uma filha vou criar". Sorri, colhe algo do chão (as fotografias) e continua: "e ela vai encher o pote pra que eu possa cozinhar". Nessa cena, os corpos dos atores se entrecruzam na frente da câmera e, num jogo de escondeesconde, a lente captura essa imagem de Lydia/Natacha segurando a fotografia. Como adverte César Guimarães: "a escritura fílmica de Moscou (...) não se contenta em somente observar o trabalho dos atores; ela distribui os seus corpos pelo espaço, seleciona o que ouve e o que capta, busca zonas de sombra ou de luz, alterna os ritmos e as distâncias" (2011, p. 77). O cantarolar que preenche o quadro, a imagem da atriz encoberta pelos corpos... não apenas a câmera, o espectador também está à espreita. Há ternura no gesto, no cochichar, no colher as fotos, no canto.

Uma outra imagem que remete à ternura é a cena em que Olga, interpretada por Inês Peixoto, carrega uma caminha de brinquedo, com fotografias coladas na cabeceira. Temos nesses objetos cênicos retratos que remetem a um mundo em miniatura, personagens presos na pequenez dos dias, como os próprios atores parecem pequenos frente ao desafio que o filme lhes propõe. Num único objeto parece estar sintetizado o encontro do teatro com o filme. Um objeto que não pode ser percebido à distância, a sua força cênica não é valorizada, dura muito pouco, é quase necessário travar o filme para ver que há fotografias, na sua maioria de crianças, e que resiste certa potência nessa fragilidade, entre a descrição de Enrique Diaz e a ação de Olga. Nessa pequena cama parece haver um passado. Nesse objeto mínimo residem o nascer e o morrer. Mas Moscou é toda ela cidade infância, não se tem como ir morrer em Moscou, assim voltamos ao início do filme.

6 Sobre Moscou, algumas análises podem ser encontradas em Eduardo Coutinho (OHATA, 2013), conferir Fábio Andrade, Ilana Feldman, Jean-Claude Bernardet, Mateus Araújo, dentre outros. 
Em Moscou, Coutinho parece querer se aproximar de algo ainda por ser revelado, mas que sabe ser impossível, pela incompletude de uma cena sem a sua presença quando pode testar a "verdade" dos seus personagens. A rememoração a partir das fotografias também não quer ser garantia de nada. Operando nesse limiar, o documentário de uma ficção, o "real" está em vias de escapar, sempre como promessa, assim como Moscou, a cidade para a qual dizem ter que ir, mas para onde nunca se vai. Seu método persiste à revelia do inacabamento e do fracasso. Em Moscou, a voz de Coutinho-narrador se junta à de Tchekhov e projeta uma cidade toda ela imaginária, toda ela devir-memória. Embora seja "um lugar que não existe", conforme Ilana Feldman abre seu texto "O filme que não acabou" (In: OHATA, 2013, p. 638), a cidade se reinventa a cada vez que é evocada, como o diretor na busca por seus personagens reinventa o método, propondo um desvio pelo direto.

Ao permitir que os atores sejam lançados nessa caixa de ensaios, como num teatrinho de sombras, borrando a fronteira entre o vivido e o ficcionalizado, Coutinho coloca questões ao método de Stanislavski em relação ao superobjetivo. Stanislavski, que foi um defensor da liberdade do ator, contrapondo ao ator autômato, diz:

Numa peça, toda a corrente de objetivos individuais, menores, todos os pensamentos imaginativos, sentimentos e ações do ator devem convergir para a execução do superobjetivo da trama. O elo comum deve ser tão forte que até mesmo o detalhe mais insignificante, se não tiver relação com o superobjetivo, salientar-se-á como supérfluo ou errado. (2006, p. 323)

Como Moscou opera no limiar e Coutinho ofusca essa zona fronteiriça entre real imediato (os anseios dos atores e atrizes durante o processo) e ficcional (que mistura lembranças pessoais e inventadas), mesmo que os atores tenham um texto e que saibam que há um documentário a ser feito, por mais que se possa embaralhar texto, fotografias de seus álbuns de família, elementos de cena, cientes da presença da câmera, a busca do diretor parece estar justamente no detalhe insignificante, nos desvios, nos lapsos da memória, na árdua tarefa do ator encontrar o personagem. Ninguém monta uma peça pensando de antemão que ela irá fracassar, para isso Coutinho faz um filme. O que parece importar é aquilo que está fora do lugar, que coloca à prova até mesmo o superobjetivo.

É da busca dos atores pelos personagens que será extraída a matéria do filme. Vale lembrar que Stanislavski nomeia um diretor, Tortsov, um "Ele", para apresentar seu método. De certa forma, se retira de cena, assim como Coutinho o faz. Enrique Diaz estaria para Tortsov, assim como Moscou para o livro A preparação do ator.

Caberia aqui a imagem da porta, figura da abertura, porém intransponível. Abertura condicional, como nos diz Georges Didi-Huberman, "ameaçada ou ameaçadora, capaz de dar tudo ou de tomar tudo de volta" (2011, p. 214). A abertura da porta, "o acesso do desejo ao seu objeto", "permanecerá virtual e, em certo sentido, interdita" (ibidem, p. 215), 
uma porta kafkiana que, segundo o autor, é "um puro enquadramento espacial" (ibidem, p. 221), uma circunscrição - como a porta desenhada por Simone Ordones/Irina com giz branco na parede escura do galpão de ensaios. O que resta aos personagens de Moscou é permanecer no limiar, há sempre a possibilidade de ir para Moscou, ao mesmo tempo, tomados pela inércia, têm um dos pés ao alcance da soleira da porta enquanto o outro permanece preso à caixa cênica. Por isso, o fora se mantém como projeção imaginária, em certo sentido, também para os personagens de Acácio.

Moscou é o filme por vir. Angola de Acácio, ao menos a Angola dos portugueses, permanece inalcançável, não há retorno possível pós-guerra colonial, quando os sonhos foram desfeitos. Embora diferentemente, Acácio e Moscou falam de uma saudade, de relações territoriais e afetivas perdidas. Nos olhos de Mariquinha é a constatação do fracasso de uma sociedade que oprime, cuja promessa de felicidade é negada desde o princípio. Talvez por isso, Dona Mariquinha, mesmo ao remeter ao passado, é toda ela presente, sua vida é uma longa jornada que se faz a pé. Desde os pés espetados no benzinho, um tipo de planta rasteira com espinho, até os pés rachados pela poeira, no sobe e desce dos morros, das escadarias irregulares de cimento: "Benzinho aqui lá longe".

Sobre a memória, César Guimarães diz algo que muito interessa à hipótese aqui levantada:

Por sua própria natureza, à memória caberia a tarefa de realizar um retorno àquilo que, a cada vez, se distancia mais e mais. Porém, exausta de repetir a repetição, sem forças para suportar o que lhe é destinado, incapaz de suportar o fracasso fundador de sua busca, a memória procura fixar-se em alguma cicatriz, corte, descontinuidade ilusória capaz de demarcar, ainda que fugazmente, o recuo incessante da origem. Diante disso, alguns textos inscrevem a memória em torno de uma origem (tomada como marco inicial do sentido) e suturam os buracos do esquecimento e o hiato entre o vivido e o lembrado. Outros, ao contrário, exibem justamente os vazios, a incompletude fundamental da memória e a dispersão do sujeito no tempo. (1997, p. 21)

Embora essa reflexão seja dirigida à elaboração textual e os filmes aqui analisados não tratem da memória de seus autores, tomando-a como empréstimo, podemos inferir que, em Acácio, Nos olhos de Mariquinha e Moscou, o corte (ou a sua cicatriz), como leitmotiv, apresenta a "incompletude fundamental da memória" e a "dispersão do sujeito no tempo". Apenas para citar um exemplo, em Nos olhos de Mariquinha, nas falas mais subjetivas da personagem, o filme altera o registro em vídeo para a memória granulada do super-8, conforme comentou Fábio de Andrade (2009), permitindo assim que as camadas temporais sejam demarcadas não apenas pela fala, mas também pela textura da imagem; o mesmo ocorre em Acácio, quando o vídeo dá lugar aos arquivos em $8 \mathrm{~mm}$ realizados pelo personagem, imagens cheias de textura e de silêncio. Moscou não trabalha com a alteração de suporte, porém essa textura, essa granulação, está propriamente sugerida 
na incerteza da elaboração de uma memória compartilhável, sendo cacos, pedaços de memórias que se dissolvem à maneira dos rebuçados na fala dos atores e atrizes. As fotografias retiradas desses "álbuns de família" exercem uma função mediadora e não parecem pretender preencher os hiatos, sendo ressignificadas no ato da rememoração pactuada entre as pessoas filmadas e realizadores e nas operações de montagem. Tais retratos, na superfície plana do papel onde foram impressos, contêm pequenas fissuras, aberturas para o fora. O que propus foi uma montagem entre elementos, em princípio, heterogêneos, buscando perceber as escolhas da realização ao lidar com esses retratos pertencentes a álbuns, caixas e arquivos pessoais, como o arquivo etnográfico de Videira. A familiaridade entre Acácio, Nos olhos de Mariquinha e Moscou reside no gesto de tatear com mão (e olhos) o passado, tornando-o mais uma vez presente na imagem.

Glaura Cardoso Vale é residente pós-doutoral junto ao grupo de pesquisa "Poéticas da experiência" do PPGCOM/ UFMG, como bolsista PNPD da Capes. É doutora em Estudos Literários pela FALE/UFMG.

glaura.cardoso@gmail.com

\section{Referências}

ANDRADE, F. Nos Olhos de Mariquinha, de Júnia Torres e Cláudia Mesquita; e Histórias de Morar e Demolições, de André Costa. Revista Cinética, 2009. Disponível em: <www.revistacinetica.com. br/tiradentes09dia8fabio.htm>. Acesso em: ago. 2009.

COMOLLI, J. -L. Ver e poder. Belo Horizonte: UFMG, 2008.

DIDI-HUBERMAN, G. O limiar interminável do olhar. In: O que nós vemos, o que nos olha. Porto: Dafne, 2011. p. 211-230.

DUBOIS, P. A. imagem-memória ou a mise-en-film da fotografia no cinema autobiográfico moderno. Revista Laika, USP, jul. 2012.

GAGNEBIN, J. M. Limiar, aura e rememoração. São Paulo: Editora 34, 2014.

GIL, I. C. Olhando as memórias dos outros... Uma ética da fotografia de Freud a Daniel Blaufuks. In: CORNELSEN, E. L. el al. Imagem e memória. Belo Horizonte: UFMG, 2012. p. 159-190.

GUIMARÃES, C. A cena e a inscrição do real. Revista Galáxia, São Paulo, n. 21, p. 68-79, jun. 2011. . Imagens da memória. Belo Horizonte: UFMG, 1997.

LISSOVSKY, M. O elo perdido da fotografia. Revista Laika, USP, v. 1, jun. 2012.

MESQUITA, C. Retratos em diálogo: notas sobre o documentário brasileiro recente. CEBRAP, São Paulo, n. 86, mar. 2010.

OHATA, M. (Org.). Eduardo Coutinho. São Paulo: Cosac Naify, 2013. 
RIBEIRO, M. C. Uma história de regressos: império, guerra colonial e pós-colonialismo. Porto: Afrontamento, 2004.

STANISLAVSKI, C. A preparação do ator. 22ed. Rio de Janeiro: Civilização Brasileira, 2006.

VALE, G. C. Acácio Videira, personagem de um filme. Minas Gerais, Suplemento Literário, v. 1318, p. 3-7, mar. de 2009.

Artigo recebido em maio e aprovado em novembro de 2015. 